\title{
Incidence of diabetic retinopathy in people with type 2 diabetes mellitus attending the Diabetic Retinopathy Screening Service for Wales: retrospective analysis
}

In the full online version of this paper by $\mathrm{R} \mathrm{L}$ Thomas and colleagues (BMJ 2012;344:e874; doi:10.1136/bmj.e874) the name of the fourth author should have been spelt "S Roy Chowdhury" [not "Chowdury"].
Cite this as: BMJ 2012;344:e1524

๑ BMJ Publishing Group Ltd 2012 